
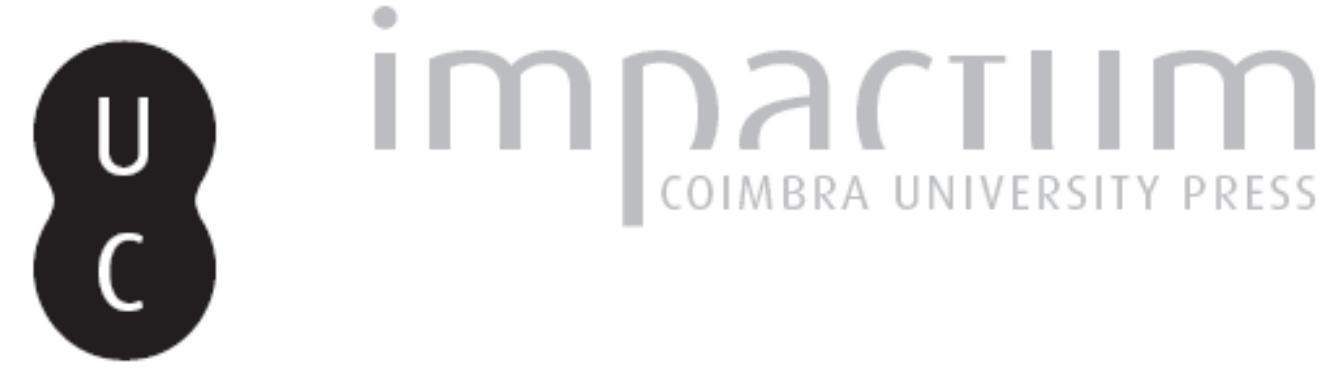

\title{
[Recensão a] La spugna è la mia anima. Omag- gio a Piero Ceccucci, a cura di Michela Graziani, Orietta Abbati, Barbara Gori
}

Autor(es): $\quad$ Vasconcelos, José Manuel de

Publicado por: Imprensa da Universidade de Coimbra

URL persistente:

URI:http://hdl.handle.net/10316.2/44990

DOI:

DOI:https://doi.org/10.14195/0870-8584_12_26

Accessed : $\quad$ 26-Apr-2023 16:33:51

A navegação consulta e descarregamento dos títulos inseridos nas Bibliotecas Digitais UC Digitalis, UC Pombalina e UC Impactum, pressupõem a aceitação plena e sem reservas dos Termos e Condições de Uso destas Bibliotecas Digitais, disponíveis em https://digitalis.uc.pt/pt-pt/termos.

Conforme exposto nos referidos Termos e Condições de Uso, o descarregamento de títulos de acesso restrito requer uma licença válida de autorização devendo o utilizador aceder ao(s) documento(s) a partir de um endereço de IP da instituição detentora da supramencionada licença.

Ao utilizador é apenas permitido o descarregamento para uso pessoal, pelo que o emprego do(s) título(s) descarregado(s) para outro fim, designadamente comercial, carece de autorização do respetivo autor ou editor da obra.

Na medida em que todas as obras da UC Digitalis se encontram protegidas pelo Código do Direito de Autor e Direitos Conexos e demais legislação aplicável, toda a cópia, parcial ou total, deste documento, nos casos em que é legalmente admitida, deverá conter ou fazer-se acompanhar por este aviso.

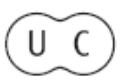




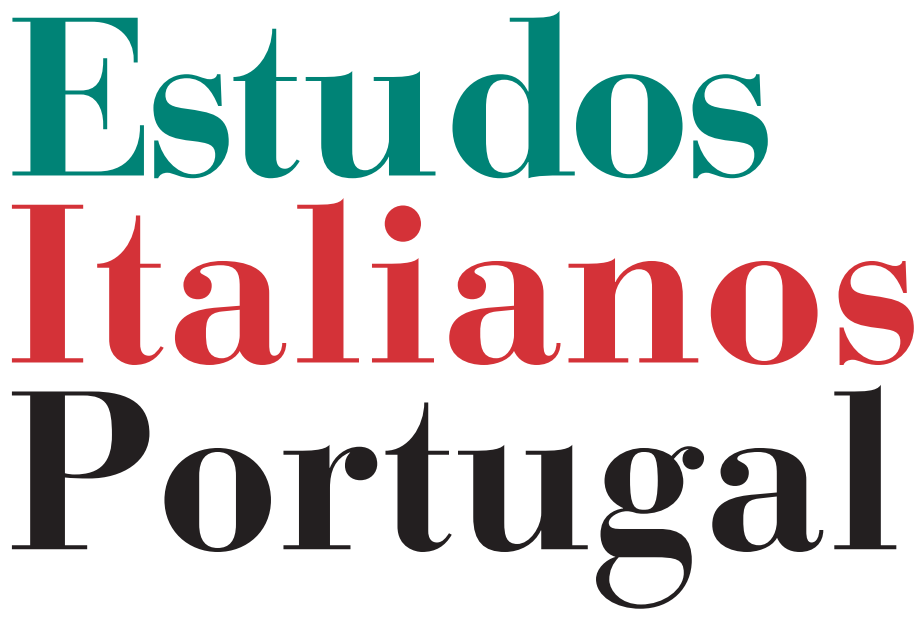

Instituto

Italiano

de Cultura

de Lisboa

Nova Série

No 12

2017 
A encerrar o volume, Mariagrazia Russo, e retornando às relações culturais entre a Itália e o contexto lusitano, trata de "La circolazione della Ropica pnefma di João de Barros nei circuiti culturali romani”. Apresenta-se aqui uma análise linguístico-estilística de uma cópia manuscrita do século XVII dessa obra, conservada na Biblioteca Casanatense de Roma. Este exemplar parece ser o único testemunho manuscrito supérstite encontrado do livro que já no século XVI circulava nos meios cultos romanos, visto que a sua edição princeps data de Lisboa, 1532. Pelo facto de se tratar de uma obra que foi incluída no Index e de poucos exemplares se terem salvado, o manuscrito assume particular importância por poder ser uma cópia de uma possível edição desaparecida da Ropica, além de atestar o relevo que alcançou, por circular inclusivamente manuscrito quer durante o século XVI, quer XVII, em Itália.

Num mundo que hoje se quer globalizado, em que a informação de qualquer ponto do planisfério se encontra ao alcance do um gesto, este volume de estudos vem confirmar como já nos séculos XV, XVI e XVII o contacto entre as duas Penínsulas, a Itálica e a Ibérica, era uma realidade indiscutível. A circulação da cultura, das informaçôes, dos textos era um dado ir- refutável, mesmo quando tal propagação ia contra obstáculos tão fortes como as proibiçõos inquisitoriais. Assim, são estudos desta natureza que hoje constituem um contributo determinante para se tornar mais transparente essa rede de contactos e intercâmbios que enriqueceu mutuamente o contexto italiano, espanhol e português, desse modo, cooperando para a génese e configuração do perfil cultural de cada nação. Manuel Ferro

\section{La spugna è la mia anima. Omag-} gio a Piero Ceccucci, a cura di Michela Graziani, Orietta Abbati, Barbara Gori, Firenze, Firenze University Press, Università degli Studi di Firenze, 2016, $538+5$ pp.

Publicado em 2016 pela Firenze University Press, La spugna è la mia anima é um volume de homenagem a Piero Ceccucci, organizado por Michela Graziani e Orietta Abbati, professoras respectivamente nas Universidades de Florença e de Turim, e por Barbara Gori, investigadora na Universidade de Pádua. O homenageado, figura bem conhecida dos mundos literários português e brasileiro, ensinou nas Universidades de Perugia, Milão, Bocconi de Milão, Génova e, ultimamente, foi professor de Língua e Literatura Portuguesa e Brasileira na Università degli Studi 
di Firenze. Com uma vasta bibliografia científica que aborda autores como Fernando Pessoa, Cesário Verde, José Saramago, Ana Hatherly, Albano Martins, Mia Couto, Clarice Lispector e Jorge Amado, entre outros, publicou ainda valiosos trabalhos sobre a acção dos missionários jesuítas no Brasil e na China. Tradutor e grande divulgador das literaturas de língua portuguesa, em Itália, é responsável pela edição italiana de $O$ livro de Cesário Verde e de uma antologia bilingue, intitulada 100 anos de poesia brasileira contemporânea. Em colaboração com Orietta Abbati, organizou e traduziu algumas obras de Fernando Pessoa, nomeadamente $O$ livro do desassossego, os contos policiários e outros contos e antologias de poemas ortónimos (Il mondo che non vedo) e heterónimos (Un'affollata solitudine). Mas, acima de tudo isso, Piero Ceccucci é um amigo grande de Portugal e dos seus escritores, da sua língua, literatura e cultura, de que tem sido incansável divulgador, não só através dos seus trabalhos escritos, mas também pela organização de colóquios, congressos e, sobretudo, dos seus cursos, nos quais têm vindo a ser formadas geraçōes de alunos interessados pelos autores de expressão portuguesa e pelas culturas dos respectivos países. $\mathrm{O}$ volume, cujo título, subsidiá- rio de Fernando Pessoa, pretende, como explicam as organizadoras, aludir, por um lado, à paixão de Ceccucci pelo poeta português e, por outro, utilizar a "ideia metafórica da esponja como material absorvente, que se deixa embeber facilmente por muitas substâncias líquidas" e "daí a metáfora da alma de Ceccucci como uma esponja, a qual no decurso da sua longa carreira universitária, pela sua sede de conhecimento, "se embebeu" de cultura lusófona, ela mesma símbolo de uma união de várias culturas europeias e extra-europeias de língua portuguesa."

De uma obra desta natureza, e dada a sua extensão considerável com mais de cinquenta contributos, não é possível numa recensão ,que se pretende não seja demasiado longa, dar a mesma atenção a todos os trabalhos e a todos os participantes. Assim, e sem que isso signifique qualquer desvalorização da qualidade e interesse dos demais textos, destacarei aqueles que, por uma razão ou outra, me impressionaram mais, procurando sempre, ainda que de forma brevíssima, apresentar as razōes que me levaram a realçá-los.

O livro, como habitualmente acontece neste género de obras, a par de textos de natureza ensaís-tica, contém depoimentos de carácter pessoal, de amigos, co- 
legas e alunos do homenageado (Testemonianze), nos quais se evidenciam qualidades, se acentuam aspectos da personalidade ou se lembram episódios ou momentos de convívio. Assim, a introdutória secção de testemunhos inicia-se com a reprodução de um trabalho plástico de Ana Hatherly, que se apresenta com uma dedicatória autógrafa da autora, intitulado "Ekfrasis", seguindo-se uma Carta Vespertina para Piero, de Lídia Jorge, na qual a escritora, referindo-se à circunstância da celebração, declara não gostar "de marcos finitos que lembram que a nossa vida não é infinita”, procurando, mais do que lamentar um acto irreversível da vida académica do homenageado, exortar a possíveis realizaçōes futuras. Há ainda uma evocação do Mestre homenageado, por Armandina Maia, um excelente texto de reflexão sobre o trabalho académico de Piero Ceccucci como lusitanista, por Paula Morão, uma digressão de recorte alegórico de Miguel Real, uma evocação de viagem, por Lilian Jacoto, e poemas de Martha L. Canfield, Nuno Júdice e Adalberto Alves. A secção termina com uma excelente tradução para italiano do conto "As cidades" ("Le città"), de Teolinda Gersão, por Gaia Bertoneri, jovem professora e investigadora da Universidade de Turim.
Seguem-se os ensaios (saggi), que ocupam a maior parte do volume, desdobrando-se por áreas diversas, embora se possam agrupar alguns trabalhos por versarem sobre temas idênticos. De resto, as próprias organizadoras cuidaram de colocar sequencialmente os ensaios, de acordo com os assuntos que neles são debatidos. Assim, Giuseppe Bellini faz desenrolar diante do leitor factos, razôes, memórias e obras que constituem o relato breve de uma história longa, aquilo que marcou o seu interesse apaixonado pelas literaturas de expressão portuguesa, bem como das literaturas hispânico-americanas, naquilo que é sempre uma "aventura incompleta"; Giancarlo Depretis, Mestre de estudos portugueses, espanhóis e hispano-americanos, dá-nos com o seu artigo uma lição notável sobre as relações poéticas no universo ibérico.

Embora tratando assuntos diversificados, podemos agrupar alguns ensaios sobre temáticas renascentistas. É o caso de Rita Marnoto, cujo ensaio aborda a viagem de Itália de Sá de Miranda e a introdução do soneto na literatura portuguesa, num ensaio de enorme rigor científico, que revela uma investigação aturada e nos dá informações e pistas do maior interesse histórico, literário e cultural; Orietta Abbati escreve, num extenso e estimulante 
artigo, sobre Giuliano Dati, figura pouco conhecida dos séculos XV e XVI, através de dois dos seus Cantari, com reprodução integral de um deles (La Gran Magnificentia de Prete Janni Signore Dell' India \& Della Ethiopia), e Anna Kalewska trata da recepção de Os Lusíadas e do mito de Camões em Itália e na Polónia. A literatura medieval está muito bem representada pelo ensaio de um notável especialista, Giuseppe Tavani, que debate as dissemelhanças temáticas do Cancioneiro da Ajuda. Ainda no âmbito da literatura renascentista, assinalamos os ensaios de Mariagrazia Russo sobre "As cartas portuguesas de Matteo Ricci no contexto da sua correspondência", importante contributo para o aprofundamento da visão que temos do famoso viajante jesuíta, e um ensaio de Carla Marisa Da Silva Valente sobre De Missione Legatorum de Duarte de Sande, obra que olha o cruzamento das visões jesuíticas e das perspectivas nipónicas na fronteira dos séculos XVI e XVII. Por seu lado, Cristina Rosa aborda a escrita autobiográfica de suor Clara do Santíssimo Sacramento. De um outro conjunto de contributos, referirei o de Pedro Eiras, intitulado "Outra nota para a redefinição da cultura", revisitação personalizada do famoso ensaio de T. S. Eliot com apoio de nomes fundamen- tais como George Steiner e do seu No castelo do Barba Azul, Jean Dubuffet e, mais distantemente, mas sempre próximo, Walter Benjamin. Annabela Rita retoma o tema do Cânone Literário, a propósito da literatura portuguesa e das expressões literárias da lusofonia, e Arnaldo Saraiva discorre acerca de argumentistas, guionistas e roteiristas.

Sobre Fernando Pessoa e temas afins, encontramos neste volume um significativo número de trabalhos, o que não será de admirar, até pelo interesse conhecido do homenageado pelo poeta, nomeadamente o estudo de um inédito, ainda quase não trabalhado, sobre um texto de Ludwig Quidde, por ele Pessoa, traduzido e prefaciado (Teresa Rita Lopes); algumas questóes de crítica textual em Álvaro de Campos (Maria Bochicchio); o Orpheu e um dos seus colaboradores (Violante de Cysneiros, ou seja, Armando Cortes-Rodrigues), por Barbara Gori. Ainda a propósito da revista Orpheu e de algumas das suas vicissitudes relacionadas com Pessoa, Egas Moniz e Júlio de Matos, podemos ler um ensaio de Jerónimo Pizarro, e um outro sobre Pessoa ortónimo, tal como se apresenta à autora do artigo (Maria Helena Nery Garcez) na edição Poesia, 1902-1917. A tradução e recepção pessoana em Itália, no caso concreto de Ruggero Jacobbi, 
figura pioneira do interesse pelo poeta português, que abdicou de o traduzir em favor de Panarese, mas que, também como uma esponja, deixou embeber a sua própria obra poética (Aroldo in Lusitania, trabalho poético publicado postumamente) pela pulsão pessoana, é ensaio bem construído e de excelente informação, de António Fournier. No que respeita a estudos sobre narrativa merecem especial menção o ensaio de Matteo Rei sobre As ilhas desconhecidas de Raul Brandão, cujo discurso é sempre abordado nas ligaçóes com outras obras fundamentais do escritor português, que o ensaísta italiano tem vindo a estudar, tendo-lhe dedicado uma magnífica tese de doutoramento, bem como ensaios e comunicações diversas. Maria do Rosário Pimentel dedica o seu contributo à infelizmente muito esquecida escritora Maria Archer, de quem a autora procura dar um vivo e detalhado retrato, destacando da sua vida os aspectos que entende terem sido mais relevantes no seu tempo e realçando o que da sua obra pode ainda hoje ser para nós motivo de interesse. António José Borges, que tem vindo a dedicar atenção a outro escritor menos lembrado, João de Araújo Correia, analisa aspectos do livro Contos durienses, relacionados com a concepção de realismo do escri- tor, e Isabel Pires de Lima leva a cabo um estudo comparativo entre Eça de Queiroz e Mário de Carvalho, destacando a importância que o escritor oitocentista tem na obra do autor nosso contemporâneo, através de referências várias que este lhe faz. Ainda no espaço queiroziano, Enrico Martines, da Universidade de Parma, trata da captação da realidade através de sugestôes e expedientes qualificados como impressionistas, centrando-se particularmente na utilização recorrente da hipálage. Petar Petrov ocupa-se dos contos de Jogos de azar de José Cardoso Pires, na perspectiva da sua escrita "cinematográfica”; Ernesto Rodrigues apresenta-nos um ensaio de distinta factura, no qual é dinamizado um discurso aliciante sobre os prazeres da literatura, através da abordagem de personagens e aspectos mais intensos do romance de Saramago História do Cerco de Lisboa; Teresa Martins Marques dá-nos, depois de um breve relance sobre o escritor e a sua obra, uma atenta visão interpretativa de Os implicados de José Manuel Mendes, obra recente que reúne umas dezenas de textos de origem diversa; Gian Luigi De Rosa ocupa-se de uma trilogia romanesca do escritor brasileiro Luiz Ruffato; Alberto Carvalho escreve um extenso texto sobre o escritor angolano Manuel Rui. 
No que se pode apresentar como uma pequena secção com trabalhos sobre questōes de linguagem e de tradução, Roberto Mulinacci explana no seu artigo considerações analíticas sobre a linguagem da Constituição brasileira, na perspectiva dos direitos e do seu reverso; Anna Tylusinska-Kowalska (com a colaboração de Joanna Ugniewska) trata de problemas e dificuldades relativas à tradução de Antonio Tabucchi para língua polaca; Salvador Pippa colabora com um texto no qual reflecte sobre aspectos linguísticos do português. No contexto dos estudos culturais relativos ao final do século XIX, designadamente no que respeita ao orientalismo, Ana Paula Avelar escolheu a obra de Rafael Bordalo Pinheiro, pondo em evidência traços orientalizantes no trabalho deste artista.

Outro assinalável grupo de estudos trata de aspectos das obras de alguns poetas portugueses e de língua portuguesa. $\mathrm{O}$ percurso poético de Manuel Alegre, desde Praça da canção a Bairro ocidental, é analisado por Giulia Lanciani, com destaque para as paisagens sociais e políticas do país à época de publicação de certas obras do escritor, que considera marcos fundamentais da sua aventura poética. Perfecto E. Cuadrado analisa as marcas hispânicas na poesia de Eugénio de Andrade, tendo como trave-mestra do seu ensaio uma entrevista dada pelo autor de Matéria solar ao jornal El País, em 2001; Maria João Reynaud aborda o Livro-Poema Trocar de século, de Alexandre Pinheiro Torres, destacando "a figura de um exilio espectral' que transparece dos vários poemas deste macropoema, em que o referente é o arquipélago de Macau; Amina Di Munno apresenta um escorço breve mas elucidativo sobre a obra e a vida de Jorge de Sena; Fernando J.B. Martinho põe em evidência, num extenso, rigoroso e documentado ensaio, os aspectos que na obra de Ana Hatherly melhor documentam a modernidade; Giorgio de Marchis ocupa-se da questão da memória dos lugares ruralizantes, percorrendo alguns livros de A. M. Pires Cabral; António Carlos Cortez aborda a sempre difícil questão das relações entre poesia e realidade, a propósito de um certo insólito que atravessa a poesia de Luís Miguel Nava; Gustavo Infante destaca e analisa os reflexos de Macau na poesia de Fernanda Dias; Mónica Simas, centrando-se na figura maior de Mário Cesariny, estuda alguns aspectos do surrealismo português, tendo como trave-mestra as forças de subversão e encantamento que caracterizaram o movimento. A encerrar o volume, Michela Gra- 
ziani, num muito bem informado ensaio, reflecte sobre o concretismo brasileiro do grupo Noigandres, com destaque para a escrita ideogramática de Haroldo de Campos. Em conclusão: estamos perante um volume cuidadosamente organizado - e não será demais sublinhar a competência, o rigor e a dedicação das organizadoras -, de grafismo adequado, sóbrio mas agradável, que, se, por um lado, é um repositório de análises críticas conduzidas por estudiosos que se especializaram nas matérias sobre as quais escrevem, de grande utilidade para consultas futuras, por outro, cumpre muitíssimo bem o seu papel determinante de homenagem, ou seja, regista para memória futura o papel fundamental que um grande lusitanista tem vindo a desempenhar na universidade e na sociedade italianas, dando a conhecer e estudando criteriosamente, e com notável profundidade, os autores e obras que lhe perecem ser decisivos para um conhecimento das literaturas de expressão portuguesa desde finais do século XIX. Um volume que o leitor interessado lerá com enorme proveito, manterá perto de si e revisitará certamente em muitas consultas, sempre que as circunstâncias e as necessidades temáticas o exigirem. José MANUEL de Vasconcelos 